Brit. J. industr. Med., 1958, 15, 41

\title{
SOME CLINICAL AND ADMINISTRATIVE ASPECTS OF OCCUPATIONAL HEALTH
}

\author{
BY \\ KENNETH P. DUNCAN \\ From the South Western Gas Board, Bath
}

(RECEIVED FOR PUBLICATION SEPTEMBER 9, 1957)

The type of work done by doctors in industry varies enormously. One man may devote most of the working week to what are essentially toxicological problems; another may be mainly concerned with what are collectively known as "hygiene" problems; almost all have varying amounts of clinical work which might be called general practice without therapeutics, or, in some instances, minor casualty procedures. In all these roles there is no lack of help and counsel in published literature and in medical meetings of diverse types. Every doctor has been well grounded in the basic sciences on which these tasks are built. In a British Medical Association publication the doctor in industry will see 13 duties listed as being appropriate to his vocation. Of these, six are almost entirely clinical, three are concerned with hygiene, two mainly demand some knowledge of toxicology, and the remaining two can be loosely called administrative. Only one fourth of one of these duties fails to fall within this rough classification and that is "advice to managements regarding accident prevention" (British Medical Association, 1949).

In reality, if a doctor is going to have anything like a full impact and influence in an industry he must concern himself with much more than these aspects alone. He finds himself entering a field for which there is no set training and in which the common pool of experience is far less fully catalogued. He wonders how far into what is apparently a management field he can go without abandoning his professional status; but he knows, or ought to know, that he cannot keep away completely from controversial ground without becoming totally irrelevant to major issues inside his own organization; the mishandling of these issues may render all his work futile.

The decision has to be made by each man for himself and these thoughts on the subject have been prompted by personal experience in constructing a new medical service, partly whole-time and partly part-time, inside a widely scattered nationalized organization. For a new service the limits have to be defined at the same time as the structure is established. It is stretching the word "welfare", used in the B.M.A.'s notes, to allow it to appear to provide the answer, but some realistic clarification of the relevance of the doctor to some of these important aspects of modern industry is urgently needed. If this is not done, occupational medicine may expand but the expansion will be uneven and its value unrealized.

It would be possible to talk of many different subjects under the heading of our title. Some present little difficulty and are not considered at all here; environmental medicine and safety work come in this category. The relationship of a medical service to the joint consultative or productivity committees of an industry is omitted because of the wide variations between one industry and another in the nature and scope of these bodies, and the same argument militates against the discussion of accident prevention. Three major subjects have been picked out and on these, it is contended, those in charge of medical services should clarify their positions: (1) Redundancy, (2) non-medical aspects of rehabilitation, and (3) the relationship with legal departments, or legal arrangements made by the employing firm.

The broad thesis is that medical departments, to exert their full influence, must be not only advisory to management but must be an integral advisory part of management, and that such an assumption does not conflict with the professional status or ethical principles of a doctor.

\section{Redundancy}

This is a topical problem in most British industries. The word "automation" resounds on every side and is frequently used with that sonority that masks ignorance. It is more often debated than defined and it cannot be defined here because it has come to 
cover a whole series of problems, the end-result of which is that the employing firm has more employees than it has jobs. The problems of redundancy stem from many roots: difficulties and changes in market conditions, improvements in organization and methods, development of new machinery; all these and other factors combine to create what looks like being the major issue on the industrial scene.

As part of the problem there is also the question of mobility of the employee. It is helpful to consider this subject under two headings, namely, the general, or policy, aspect, and the particular, or individual case, approach.

General Policy.-Immediately it is suspected that a reorganization is likely, it becomes evident to the employee that redundancy is possible. The first reaction of many is fear. In an industry which has for years followed a conservative development path the security of employment has come to be accepted as part of the natural order of things. Whether this is wise or unwise has nothing to do with the case, it is simply a fact. The consequences of this attitude, and of its sequel, fear of loss of status, will be dealt with under the more particular approach, but here it is necessary only to point out, as is now fairly generally accepted, that the only possible minimizer of those natural anxieties is early and full consultation between management and employees. The good doctor in industry will know from his contacts at all levels how successful or otherwise that consultation is, and it is his clear duty to give the management his views on the point. His function in the maintenance of group morale is never more clearly seen.

One of the important facts of this consultation is that it must be, as far as possible, specific. In other words, certain clear promises have to be made. Apart from specified categories of employees, the principle may well be "first in, last out", but that is not always easily applied in practice, especially as increased efficiency is usually part of the object. In any case, what are the exceptions to be? Should disabled persons be exempted? If only some of this group are exempted, how are they to be chosen ? Should a distinction be drawn between married men with families and single men ? There is no method of effective selection that will not lead to some heartburning but at least the lines should be clear so that the ill-effects of suspense are minimized. It is my view that the doctor's advice at this level can be clear. There should be no medically protected categories. Just as disability should not be a bar to suitable employment, so it should not be a shield when hardships fall to be widely borne. It is implicit in this approach that the percentage of registered disabled employed would not be allowed to fall below the required minimum but most industries appear to carry far more than that figure and in any case the larger number of disabled are not registered, though their problems at times of redundancy are no less. Almost all such situations and solutions must, however, contain a " hardship " clause if the industrial relations are not to be completely depersonalized. It is from the operation of this clause, not only against dismissal but against mobility, that much of the doctor's hardest work will come and it is here that his strict and hard-won reputation for impartiality will stand him in good stead. Perhaps this refusal to use any sort of medical umbrella sounds harsh, but it is my view that it must be accepted and that to state the reverse is sentimentality. The need for complete fairness of treatment is so great and its genuineness and visibility is so essential to group morale that the doctor must appreciate its place when he looks at the wider canvas.

There is another aspect of importance which must be borne in mind when considering a re-organization. It is probable that, with a redundancy to be faced, a firm will be loth to seek outside applicants for vacant posts. In other words, the smaller number of jobs which will demand a higher calibre of employee will be filled from inside the organization; quite often it is found that changes have come too suddenly to allow of a gradual maturing towards these more demanding centralized posts. Sometimes this works out better in practice than might be expected but the hazard of the procedure should be clearly seen by a doctor and he should be on hand to advise any who find the pace of the race getting too hot without any delay. Kennedy (1957) has summarized the causes and the early symptoms most clearly and a syndrome, too long unrecognized, should now be regarded as defined.

Individual Cases.-If a hardship clause is to be operated it must be dispassionately used. Nowhere is it more difficult to tell black from white than in the matter of early retirement pensions which the rules of some schemes make available only on illhealth grounds, or sometimes on better terms if the retirement is brought about by illness or injury. What are the limits of valid medical grounds ? Indeed, how far can certain facts be called medically relevant at all ? Cases will illustrate the dilemma as it occurs in this industry. The distinction between illness, particularly psychological illness, and general inefficiency can be extraordinarily difficult but it is dangerous for medical certification to be an easy way out of management problems. 
Case 1.-A reorganization was taking place in an area where early retirement pensions were poor except when the retirement was on grounds of ill-health. A senior clerk presented a placement problem in the new plan and yet he had good qualifications for retention by virtue of past service. It was felt that he might not be very efficient in the new scheme of things. The medical facts were that in the past he had had diverse vague complaints such as mucous colitis and coccalgia but at the time of examination he appeared perfectly well, apart from the fact that he was, as he had always been, of an introspective nature. He would have been quite pleased to go out on grounds of ill-health but not under voluntary early retirement, and the management were eager that he should be certified in this way. In spite of this agreement certification was refused and in the event he has been accommodated in the new organization.

Was the refusal correct ? In my opinion it was. There were some medical aspects but these were not sufficiently potent to prevent the individual doing the tasks available for him. In a sense it could be said that the doctor acted against his patient's interests, but if a doctor does only what his patient wants him to do, inside or outside industry, his influence and status will soon go. Similarly, if working inside industry he does only what the management thinks to be expedient, his reputation for impartiality is finished. Nonetheless, it can be extremely difficult finding firm ground to stand on in many cases, and not infrequently a professional colleague, who sees only one side of the picture, will be offended at the stand taken, even when he is most carefully consulted about the matter.

On another occasion it was deemed necessary for a fair number of employees to move to another part of the area as part of a reorganization. There were a few jobs remaining in the old location and it was agreed that those with the longest service could have these posts if they wanted them, the only exception to the priority being those with compelling medical or "welfare" reasons.

Case 2.-A man under supervision for tuberculosis, which was now quiescent, brought a medical certificate in support of his claim. Here again there was no disputing the disability but support for the claim was refused on the grounds that his condition was not a bar to movement and the medical reasons which went with it were no more urgent than the non-medical grounds relied on by men who were not disabled.

Case 3.-Another fairly senior official was informed that he must, as a result of re-organization, move his house about 30 miles. The only theoretical grounds of appeal were medical and he advanced a plea on the ground of his wife's health. She had secondaries in the spine arising from a breast cancer and was undergoing deep $x$-ray and other treatment under a consultant in whom she had great trust. It was argued by the manage- ment that any treatment would be available in the proposed new location, but a certificate was thought justified in this case.

The great majority of cases are fairly straightforward and, with goodwill on all sides, can be solved amicably in a way that is patently fair all round. The real difficulty arises when there are mixed organizational, welfare, and medical factors, and no one factor is itself large enough to warrant deviation being based on it. An isolated doctor in his ivory tower cannot hope to elicit or comprehend all the aspects involved and is bound to be either so equivocal in his opinions as to be totally unhelpful, or to be biased in one direction or another.

The insecurity engendered by redundancy is not merely a fear of loss of occupation or even loss of earnings, but is very often a fear of loss of status. The man who has been for years chief clerk of some tiny, independent unit, may not have had much salary, but he has been a person of standing and consequence in his own organization, his own town or village, or in his social activities. He can be compulsorily moved to a larger group without loss of cash, indeed even with promotion, yet may exhibit emotional symptoms, quite often with physical sequelae, which a trained industrial medical officer can do much, by explanation and understanding, to prevent or relieve. It is a commonplace to hear from such individuals, "I wanted to talk to you about it because I knew you were aware of all that went on at work". His belief may be exaggerated but at least it shows that the doctor's attempt to become part of the industry has succeeded. It is my contention that there is far more real work to be done on this aspect of occupational health than there is on the hygienic and toxicological side, and that the development of this work is the most constructive step that can be taken against the psychosomatic diseases which appear to increase even faster than the environmental diseases diminish. It is a recurring, pleasurable surprise, even to those not psychiatrically trained, to discover how much can be achieved by frank discussion of apparently insoluble problems.

Much of what has been said refers to clerical staff but the need for the work is no less on the manual side. A considerable number of people remain faithful to one industry and become jealous of their status within it. The tendency is for larger and more streamlined organizations and the danger of depersonalization is great. There is an important and developing part for a doctor to play, provided he integrates himself with all levels of his organization and provided he learns a new approach to the wide range of quasi-medical problems. He takes a risk in emerging from his chromium to do this but he can 
achieve little if he declines, or is refused the hazard. Some of the problems he takes on may rightly be called non-executive functions of an enlightened management but if he will not accept them, no one else may and the historic bitterness between employer and employed is not yet diminished enough to make unhelpful the availability of a fair, neutral, " third force". The particular problems of each employee are unique in his own estimation, and unless he feels that they have had special, impartial, examination, he will never believe that he has been justly treated. The problems of re-adaptation are individual in exactly the same way. Hardship there will certainly be, but it can be understood and limited. There are many ways of helping and the doctor in industry must be familiar with them. Even when little practical assistance is possible, his moral support should be available freely to all.

\section{Administrative Problems in Rehabilitation}

When a man has injured the tendons of his thumb and treatment has progressed to the point where increasing exercise is advantageous, there may be relatively little difficulty in employing him in a fully productive way which is not only helpful to him but also useful to his employers. The same is true of most orthopaedic cases. Unfortunately, limb disabilities form a relatively small part of the rehabilitation problem and in all types of case the actual selection of suitable work is only one of many problems. Every occupational medical service must include some " getting back to work" arrangements. In some cases it has been found possible to provide special workshops, special machinery and other physical facilities, but the first step is to provide the right attitude to rehabilitation inside the industry. Unless that is achieved the material provisions are worthless. It is also important to remember that the right attitude has to be created among the workmen as well as among the employers; a surprising number of resettlement difficulties are caused by colleagues who might be expected to be particularly helpful but whose helpfulness stops short of any infringement of their own alleged rights. In discussing plans with management or men's representatives, great care has to be taken to steer a middle course between the emotional approach and considering employees as financial assets. It is easy to build up a most moving case, especially about the more visible deformities or those in the news for which the general public like to express that emotion which pretends to be sympathy; it is easy to impress with talk of being injured in the company's service, as if the consequences of that were more soul-searing than being injured in any other way. On the other side of the picture, it is impossible to prove financial gains from a rehabilitation programme and even if this could be done it would not be the point at issue. The rehabilitation facilities of an industry, however complex or simple they are, should be open equally to all who can make use of them, irrespective of how they came by their disabilities. In no other way is it possible to avoid the charge that " kissing goes by favour ".

However elaborate or simple a rehabilitation plan is, there are certain problems associated with it which must be faced if the plan is to have any hope of success. As a doctor one hopes for its success but a starry-eyed detachment from such facts of industrial life as " rates for the job", " promotion by service only", and the maze of little rules, written and unwritten, existing in every organization will not help. In this industry we were particularly handicapped by a sick pay scheme which, after certain conditions were fulfilled, gave $100 \%$ sick pay for 13 weeks to all manual workers, and for longer spells to other grades.

Case 4.-A semi-skilled worker had been absent for about 18 months because of tuberculosis. According to the rules of the sick pay scheme he became entitled, as from a certain date, to a further three months' full sick pay. Shortly before this date he came back with a recommendation that if suitable work could be found he could start on a four-hour day. He was hardly delighted to discover that his pay for working within his physical limitations was about half his pay for remaining on the sick list. Similar cases occurred among clerks on other conditions of service.

Case 5.-A shiftworker was absent on sick pay and when he was seen it was decided that, while he was unfit for his own job, he could do another day-work job which was available. His doctor was quite happy to go on issuing certificates as he was unfit for his normal work. While sick he drew nearly one-third more money than he did when alternatively employed.

It is true that men who can do some useful work should not be drawing sick pay. It is true that rehabilitation is in the patient's physical interests. Nonetheless, contradictions such as these instanced have to be dealt with before there is any hope of success. In our particular case, the relationships with other departments have been happy and it proved possible to pay an employee his sick pay entitlement as his rate while he was at work in these circumstances. Otherwise, the rate for the job applies. In another industry a different compromise has been reached whereby the man is paid the difference between his old and new rate but there is a proviso that he shall not drop more than 10s. a week in a re-adjustment job provided that it is 
certified that he should eventually be fit to return to his normal work.

It is not a doctor's job to make decisions about these matters but, especially in a new service, it is his work that will raise the problems and he cannot s'rug them aside as being irrelevant to him since their solution is vital to the success of his efforts.

Stewart (1954) makes the statement that every firm employing more than 7,500 on one site should consider the setting up of a special rehabilitation workshop, and it is probably fair to say that every firm of that size should be able to absorb all its own disabled from all causes, with one or two minor special category exceptions. On the other hand, a relatively small proportion of the working population is to be found in such large undertakings and, in spite of many committees and large expenditure by public and voluntary authorities, the replacement of the sick and injured in suitable work is probably the weakest link in the therapeutic chain in this country. There seems no reason to believe that the expenditure of more money or the building of more centres would notably help with this problem. Giving a man a broom and hiding him in a corner is not rehabilitation. Sending a man on a long training course and then not using that training is no better. Far the best place in the recovery stage is the patient's normal workplace and a survey of the system of work is often as important as a job analysis of the patient's particular employment.

Case 6.-A man who worked in a meter repair shop had been off sick for about 18 months with rheumatoid arthritis. He worked with two colleagues-loading, unloading, examining, recording, and stacking meters. The meters weighed only $12-20 \mathrm{lb}$. on the average, but he was in a wheel-chair and that work was clearly beyond him. It proved possible to persuade his colleagues to re-organize the system of work in such a way that the patient did the sedentary clerking and examining. He came back on this basis and when last seen was fetching and carrying in the same way as before his illness.

He would not have made a satisfactory clerk in any other place and, in any case, the deciding factor in his re-adaptation was almost certainly that it was carried out in his own familiar environment.

If a doctor takes the trouble to learn his own industry and more particularly to become known to the employees and to share his plans and problems with them, there are few insoluble rehabilitation cases and any minor roughness of facilities is more than compensated for by psychological gains.

The management may have to be persuaded that their factory is not being converted into a convalescent home-sickness records of disabled persons are often valuable for this-and the employees have to be persuaded that their hard-won agreements are not being carelessly or dangerously circumvented. The patients, particularly the neurotic group who form a large proportion of placement problems, have to be convinced that ordinary work can be rehabilitation and that once found such work they are expected to do it properly. Minor concessions, such as travel out of rush hours, should be closely watched and whenever possible should be temporary. The strictest precautions against abuse are essential if the value of the facilities is to be appreciated and a long queue outside a works physiotherapy department is the antithesis of a successful rehabilitation programme.

Much stress has been placed on the assessment of physical function in diverse disabilities; a fair amount of work has been done on job analysis; very little attention has been given to the significance of group attitudes to the disabled man. It is on non-medical questions that most rehabilitation programmes run into their worst difficulties.

\section{Relationship with Employing Firm's Legal Arrangements}

While it has been emphasized that an industrial medical officer must be an advisory part of management and not just an adviser to management, it must be admitted that the appellation " the management's doctor" is, in many ways, a damaging one. It is widely held, even by professional colleagues outside the industrial field, that in some subtle way the doctor in industry has sold his soul to his employer and is incapable of giving a balanced, independent opinion. This, if it were true, would be a grave state of affairs since it would strike at the very heart of the doctor-patient relationship, which needs to be as unfettered by suspicion in this sphere of work as in any other. The feeling of bitterness, which is often the concomitant of the processes of the law, makes any advice on matters under litigation a dangerous exercise for the doctor. On the other hand, it is not always possible to stand aside from these matters.

Case 7.-A workman sustained an injury which led to a mid-thigh amputation. The circumstances of the accident (not covered by the Factories Acts) were not clear but it appeared that an unsafe system of working had been employed and that the employer's agent was to blame. There had been no contributory negligence by the victim. When the man returned to a suitable job which had been found for him he had a considerable loss of earnings retrospectively and of earning power prospectively. He was a simple soul who was not a paid-up member of his Union and had, surprisingly enough, taken no steps towards a claim in common law. The 
financial hardship to the man and his family was considerable.

The course adopted in this case was probably cowardly. Senior professional colleagues were consulted and the variation in their advice was, in any case, more confusing than clarifying, but fortunately, while all this was going on, someone else advised the patient to consult a solicitor.

It is an awkward position for a doctor to be the instigator of litigation but yet the man's need and rights should probably have been an overriding factor.

The position frequently arises that an industrial medical officer is asked to assess a case in which a claim has already been made. He should be confident of his ability to give a fair appraisal but he will learn from experience that, even if a report agreed with the patient's private practitioner is produced, this is one instance where he will never be believed to be truly impartial.

It is my opinion that when the patient in these issues comes from inside the industry, the doctor should come from outside. It is unfortunate that, in some industries, doctors have been engaged to "protect the interests of the management", and such a position must be avoided at all costs. The attitude of management and men towards these claims appears to be perpetually emotionally charged and it is better to retreat from an impossible situation than to endanger the reputation for independence of mind which is essential to the discharge of occupational health duties.

\section{Conclusion}

Much has been written and spoken about the need for an extension of occupational health services. There is available a wealth of published information on most of the diseases associated with industrial processes and much of this information seems to repeat itself in rather tedious cycles. There is, however, very little to guide the newcomer to the industrial field on many matters which he finds to be of much more frequent impact; all too often he is allowed to become irrelevant to the main events in his own industry because of personal diffidence or because of his deliberate abstention from what he considers to be " non-medical" topics. Environmental health facilities will improve; that appears to be a well-established trend. It is, however, not by influence on the physical environment alone that an industrial medical officer should be judged but by his influence on individuals and groups. In the last analysis "industry" means people at work and no amount of mechanization will make that statement false.
It is a discouraging fact that, in spite of all the advances in all branches of medical science, the general healthiness of mind and body of the community makes little or no progress. As sanatoria empty, mental hospitals fill; as nutritional defects diminish, cancers increase; as industrial poisonings become less frequent, stress diseases, mental and physical, multiply. Although it is generally accepted that the working hours have less to do with psychological trauma than the domestic ones, it is the claim of doctors who work in industry that by being known as part of the team they can exert a powerful influence for good on the positive aspects of the health of their companions, at all levels in the industrial structure.

This claim becomes nonsense if they are not accepted as part of the team. They cannot be so admitted unless they learn the facts of industrial life. There is a need for much work on the relevance of the arts of medicine to these problems and for pooling of experience, which alone can ensure that the same old errors are not endlessly and needlessly repeated.

The multiplication of casualty clearing stations, with a full complement of starch and chromium, will not denote the advance of occupational health, but an increasing tendency to bring trained doctors into consultation on many matters apparently far removed from the consulting room will. Those of us who hope for such an advance must do a great deal of fundamental preparatory thinking and research.

\section{Summary}

The attitude of an industrial medical officer to personal and general problems stemming from re-organization, redundancy, rehabilitation, and compensation inside industry is discussed. Some of the practical difficulties are illustrated and the view is expressed that only by becoming an integral advisory part of management can the doctor make his full contribution to the common good of all those working with him in the industry. The need for further studies of the impact of change and of the organization of internal rehabilitation and placement schemes, however primitive, is stressed.

I wish to thank Mr. C. H. Chester, C.B.E., Chairman of the South Western Gas Board, for permission to publish this paper. The views expressed are those of the author and do not necessarily represent the views of the Board.

\section{REFERENCES}

British Medical Association (1949). Duties of and Ethical Rules for Industrial Medical Officers.

Kennedy, A. (1957). Lancet, 1, 261.
Stewart, Donald (1954). In Industrial Medicine and Hygiene, Vol. 1, p. 285, ed. Merewether, E. R. A. Butterworth, London. 